\title{
Left-to-right processing of alphabetic material is independent of retinal location
}

\author{
LESTER A. LEFTON \\ University of South Carolina, Columbia, South Carolina 29208 \\ DENNIS F. FISHER \\ U.S. Army Human Engineering Laboratory, Aberdeen Proving Ground, Maryland 21005 \\ and \\ DONALD M. KUHN \\ University of South Carolina, Columbia, South Carolina 29208
}

\begin{abstract}
The effects of retinal location, serial letter position, and order of approximation to English on the accuracy of report of tachistoscopically presented letter arrays were examined. Processing time was controlled by a visual mask. The results show the following: (1) Overall accuracy is higher for arrays which appeared symmetrically around a central fixation point than for arrays which appeared either in the right or left visual field. (2) The first and last letters of an array are identified with the greatest accuracy except with symmetrical arrays. (3) Fourth-order approximations are more accurately reported than first-order approximations at each retinal location and at each letter position with the exception of the first and last letters. (4) Retinal location interacts with serial position in such a way that letters in middle positions are primarily affected by retinal location. (5) Letters are processed from left to right regardless of retinal location.
\end{abstract}

When individual English letters or words are presented to only one visual field (unilaterally), accuracy is highest for stimuli to the right of fixation (Bryden, 1967; Heron, 1957; Mishkin \& Forgays, 1952; Wolford \& Hollingsworth, 1974b; see White, 1969, for an extensive review). When an array of letters crosses into both visual fields (bilaterally), with central fixation, the shape of the percentage correct response curve becomes task dependent. In partial-report experiments, subjects are required to identify a single or selected probed item and the response curve assumes the shape of a W, indicating that performance is highest and reaction time is fastest at the center and extreme ends of the display (Haber \& Standing, 1969; Hershenson, 1969; Lefton, 1974; Lefton \& Haber, 1974; Merikle, Lowe, \& Coltheart, 1971; Smith \& Ramunas, 1971). In full-report experiments, subjects are required to report all items and the response curve tends to be asymmetrical, i.e., accuracy decreasing and reaction time increasing from left to right (Bryden, 1967; Crovitz \& Schiffman, 1965;

This research was supported by grants from the National Institute of Education (NE-G-00-3-0017) and the U.S. Army Human Engineering Laboratory and Army Research Offices (DAAG 29-77-G-0035). No official endorsement of NIE or ARO should be inferred. This paper may be reproduced in full or in part for any purpose of the United States Government. Requests for reprints should be sent to Lester A. Lefton, Department of Psychology, University of South Carolina, Columbia, South Carolina 29208.
Lefton, 1974; Merikle et al., 1971; Mewhort, Merikle, \& Bryden, 1969). However, when subjects are specifically instructed to report in a right-to-left direction, the rightmost characters are reported quite accurately (Estes, Allmeyer, \& Reder, 1976; Mewhort \& Cornett, 1972).

The W-shaped function typically found in partial report experiments with bilateral arrays is more complex. The greater accuracy in the center is probably attributable to central fixation (i.e., that item is clearer since it is foveal) (Hershenson, 1969; Lefton, 1974; Wolford \& Hollingsworth, 1974b). The greater accuracy at the ends of the display is probably due to the lack of spatial masking by surrounding letters (Haber \& Standing, 1969; Lefton, 1974; Wolford \& Hollingsworth, 1974a) and to less positional and discriminative uncertainty (Estes et al., 1976; Geoffrion, 1976) in these positions relative to more central characters in the array.

When the letters in an array closely approximate English, they are more accurately and quickly processed than are random strings of letters, the difference in accuracy being greatest on the right-hand side of the array (Lefton, 1974; Merikle et al., 1971; Mewhort et al., 1969; Miller, Bruner, \& Postman, 1954). It is possible to account for this right visual field superiority by considering the projection of the right retinal field to the left language-processing cortical hemisphere (Bryden, 1967; Estes et al., 1976; Heron, 1957), to changes in subjects' strategy (Lefton \& Haber, 1974), or to 
altogether different types of processing (Wolford \& Hollingsworth, 1974b).

This brief overview is not intended to be exhaustive but to demonstrate the importance of such variables as type and order of report, familiarity, letter position and spatial masking, and retinal location in determining the accuracy of the extraction of information from briefly presented stimuli. In the present experiment, the first or the last letter of the array appeared at fixation (cf. ARRAY, ARRAY: ARRAY), with fixation always centered. This experiment investigates the function of familiarity, retinal location, and letter position under conditions where the stimuli are not symmetrically arranged around fixation but are situated completely to the left or right of it.

\section{METHOD}

\section{Subjects}

Subjects were 20 volunteer graduate and undergraduate students at the University of South Carolina. All had normal or corrected vision and were right-handed.

\section{Stimuli}

The stimuli were first- and fourth-order approximations to English taken from lists in Hirata and Bryden (1971). Because these lists contain only 40 items per order of approximation, we included 20 items from the third order with the 40 items of the fourth order (referred to hereafter as fourth order for simplicity). Likewise, 20 items from the second order were included with the 40 items in the first order (referred to hereafter as the first order). Thus, 60 stimulus cards for each order of approximation (first and fourth) were prepared. Each sequence was seven letters long and contained no repetition of letters. Stimuli were prepared with uppercase black transfer letters (Letraset Letters, Futura Bold, No. 108) placed on white stimulus cards. The array of letters presented at $85 \mathrm{~cm}$ subtended a visual angle of $3.5 \mathrm{deg}$ horizontally and $.40 \mathrm{deg}$ vertically. A fixation point was provided in the center of the field, and the letter strings were presented in one of three configurations: (1) symmetrically, with the fixation point centered just below the array, (2) fixation just below the first letter of the array with the array extending primarily into the right visual field, or (3) fixation just below the last letter of the array with the array extending primarily into the left visual field. It should be emphasized that the fixation point was always in the center of the visual field. An example of the stimulus arrangement is presented in Table 1. The stimuli were presented in a Gerbrands tachistoscope (Model T-3B-1C). The background luminance was equated at $40 \mathrm{~cd} / \mathrm{m}^{2}$ in each field.

\section{Procedure}

Subjects were familiarized with the operation of the tachistoscope and informed about the nature of the stimuli during a 5-min dark-adapting period. After fixation, the subject initiated

Table 1

Sample Display Depicting the Three Stimulus Configurations

\begin{tabular}{lllllllllllll}
\hline \multicolumn{11}{c}{ Letter Position } \\
\hline 6 & 5 & 4 & 3 & 2 & 1 & F & 1 & 2 & 3 & 4 & 5 & 6 \\
\hline D & L & I & M & B & E & R & & & & & & \\
& & & H & E & M & I & N & D & O & & & \\
& & & & & A & P & O & N & S & T & E \\
\hline
\end{tabular}

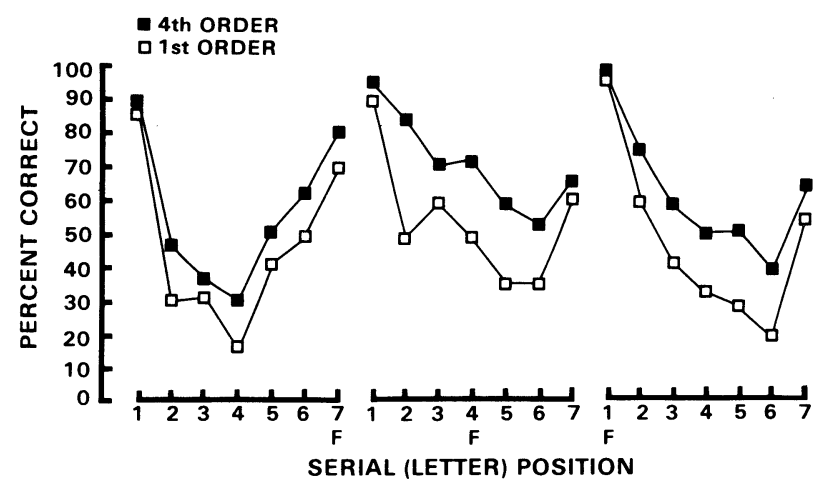

Figure 1. Mean percent accuracy for fourth- and first-order approximation is presented as a function of serial position. The leftmost panel shows data when fixation is on the right, the middle panel when fixation is central, and the rightmost panel when fixation is on the left.

each trial by depressing a microswitch. Subsequently, a letter array appeared for $75 \mathrm{msec}$, followed by visual noise mask of crosshatches which completely overlapped the entire array. Subjects were instructed to report as many letters as possible and to guess if not completely sure about a letter. Twenty practice and 40 test trials at each of the three different stimulus configurations, were presented in random order in the experiment. Each stimulus appeared only once.

\section{RESULTS}

The number of correctly identified letters for each position for each subject was calculated and entered into an analysis of variance, with retinal location (left, right, or center), letter position (1-7), and order of approximation (first or fourth) as within effects. The main effects of retinal location $[F(2,38)=43.7]$, letter position $[F(6,114)=91.9]$, and order of approximation to English $[F(1,19)=154.7]$ were all significant at the .001 level or beyond. The interactions of Letter Position by Order of Approximation $[\mathrm{F}(6,114)=17.9]$, Letter Position by Retinal Location $[\mathrm{F}(12,228)=32.7]$, and Order of Approximation by Retinal Location $[F(2,38)=14.3]$ were all significant at the .001 level as well. The Letter Position by Order of Approximation by Retinal Location $[\mathrm{F}(12,228)=2.99]$ triple interaction also reached significance at the $p<.001$ level. These data are plotted in Figure 1.

It can be seen in Figure 1 (center panel) that accuracy is the highest for letters presented symmetrically around fixation, evidenced with W-shaped curves. The curves in the left and right panels evidence more characteristic serial position curves, with highest performance at Positions 1 and 7. Retinal location and letter position interact in the left and right curves in such a way that letters in the middle positions are reported less accurately than those in the end positions. (Overall accuracy for Position 1 was $92.1 \%$ correct and for Position 7 was $65.3 \%$.) 
The order of approximation effect is also quite evident. The fourth-order approximations were reported with $63 \%$ correct, compared to $48 \%$ correct for firstorder approximations. The order of approximation effect was significant at all retinal locations except Positions 1 and 7, with the greatest difference occurring when the letters of the array were arranged symmetrically around fixation (Figure 1, center panel).

Additional analyses were performed on those data from conditions where the stimulus array was projected into the right or the left visual field (Positions 1 or 7 at fixation, respectively). Accuracy for the right vs. left visual fields for each order of approximation was assessed separately. The percent correct for first-order approximations was $46.1 \%$ for left vs. $47.3 \%$ for the right visual field stimuli; the difference between these means was not significant $(t=.154, d f=6)$. For fourth order approximations, left visual field accuracy was $56.2 \%$ correct compared to an accuracy of $62.0 \%$ for the right visual field. Again, the difference between these means was not statistically significant $(t=.842, d f=6)$.

\section{DISCUSSION}

The results of the present study corroborate and extend the findings of several studies on the extraction of information from briefly presented letter arrays. When stimuli were presented symmetrically around fixation, accuracy of report was highest at Letter Position 1 for both orders of approximation. Accuracy declined from left to right with a slight discontinuity at fixation (W-shaped curve), increasing again for both orders of approximation at the last letter, Position 7. The typical Uor backward-J-shaped curve resulted when the array totally occurred left or right of fixation. Letters in the fourth order were reported more accurately than those in the first order, reflecting the combined influence of a sequential left-to-right processing which proceeds faster for fourth-order approximations because of the familiarity effect created by English orthography (Lefton, 1974; Lefton \& Spragins, 1974; Merikle et al., 1971; Mewhort et al., 1969; Miller et al, 1954).

The higher levels of accuracy typically seen at the two extreme ends of an array may be accounted for in any of several ways. First, these letters are bounded by other letters on one side only, being subjected to little, if any, spatial masking (interference) by adjacent letters (Haber \& Standing, 1969; Lefton, 1974; Townsend, Taylor, \& Brown, 1971; Wolford \& Hollingsworth, 1974a). Furthermore, discriminative and positional uncertainties contribute to accuracy of letter identification (Estes et al., 1976; Geoffrion, 1976). Subjects have to identify not only stimulus features but also their spatial location within the array. Thus, the end letters of an array are subjected to little discriminative or positional uncertainty, enhancing correct identification.

Also, the topography of the serial position curves in fullreport procedures (otherwise unconstrained in terms of processing or reporting order) generally assumes the shape of a backward $\mathbf{J}$ (see Figure 1, right panel), with accuracy greatest at the left-hand side of the array and declining steadily for letters in the right-hand side of the array. This reliable result is taken as evidence for a left-to-right directionality in processing information out of iconic memory (Lefton \& Spragins, 1974; Mewhort et al., 1969).

Alternative explanations for a left-to-right asymmetry in serial position curves might include notions of memory load (Estes et al., 1976) and order of output report effects (Holding,
1974). However, Lefton and Spragins (1974) and Mewhort et al. (1969) convincingly argued from masking studies that processing of tachistoscopic letter arrays proceeds from left to right even though order of report variables can potentially contaminate the results (Lefton, 1974). The results seen in Figure 1 are consistent with an impressive body of literature demonstrating a left-to-right information processing mechanism even though the subtle W-shaped curve emerges in the center panel.

Many variables obviously contribute to letter recognition in visual information processing tasks. Recently, Wolford and Hollingsworth (1974b) demonstrated that accuracy of report of the center letter positions was dependent upon fixation location. The most interesting and salient aspects of the present results are related to this observation. When the array extends to the left or to the right visual field (Figure 1, left and right panels, respectively), accuracy at the middle positions declines. However, this is not the case when the middle serial positions are at fixation, for then these are reported more accurately than surrounding items (Figure 1, center panel). The similarities between these data and those of Wolford and Hollingsworth (1974b) for seven letter positions are striking. However, their larger arrays (nine letters) resulted in smaller up-turns in the recency position than those found here.

We conclude that, even with very divergent retinal locations and without specific instructions, subjects process letter arrays in a left-to-right direction. The scanning and familiarity effects created by the orthographic constraints of English are dependent only in magnitude on such variables as retinal location and letter position and reflect processing, not the effects of purported output variables.

\section{REFERENCES}

BRYDEN, M. P. A model for the sequential organization of behavior. Canadian Journal of Psychology, 1967, 21, 37-56.

Crovitz, H. F., \& Schiffman, H. R. Visual field and the letter span. Journal of Experimental Psychology, 1965, 70. 218-223.

Estes, W. K., Allmeyer, D. H., \& Reder, S. M. Serial position functions for letter identification at brief and extended exposure durations. Perception \& Psychophysics, 1976, 19, 1-15.

Geoffrion, L. D. Positional uncertainty in lateral masking and the percpetual superiority of words. Perception \& Psychophysics, 1976, 19, 273-278.

HABER, R. N., \& Standing, L. Location of errors with a post-stimulus indicator. Psychonomic Science, 1969, 17, 345-346.

Heron, W. Perception as a function of retinal locus and attention. American Journal of Psychology, 1957, 70, 332-337.

Hershenson, M. Perception of letter arrays as a function of absolute retinal locus. Journal of Experimental Psychology, 1969, 80, 201-202.

Hirata, K., \& Bryden, M. P. Tables of letter sequences varying in order of approximation to English. Psychonomic Science, 1971, 25, 322-324.

Holding, D. H. Sensory storage reconsidered. Memory \& Cognition, 1974, 3, 31-41.

Lefton, L. A. Probing information from briefly presented arrays. Journal of Experimental Psychology, 1974, 103, 958-970.

Lefton, L. A., \& HABER, R. N. Information extraction from different retinal locations. Journal of Experimental Psychology, 1974, 102, 975-980.

Lefton, L. A., \& Spragins, A. B. Orthographic structure and reading experience affect the transfer from iconic to 
short-term memory. Journal of Experimental Psychology, 1974, 103, 775-781.

Merikie, P. M., Lowe, D. G., \& Coltheart, M. Familiarity and method of report as determinants of tachistoscopic performance. Canadian Journal of Psychology, 1971, 25, 167-174.

Mewhort, D. J. K., \& Cornett, S. Scanning and the familiarity effect in tachistoscopic recognition. Canadian Journal of Psychology, 1972, 26, 181-189.

Mewhort, D. J. K., Merikle, P. M., \& Bryden, M. P. On the transfer from iconic to short-term memory. Journal of Experimental Psychology, 1969, 81, 89-94.

Miller, G. A., Bruner, J. L., \& Postman, L. Familiarity of letter sequences and tachistoscopic identification. Journal of General Psychology, 1954, 50, 129-139.

Mishkin, M., \& Forgays, D. G. Word recognition as a function of retinal locus. Journal of Experimental Psychology, 1952, 43, 43-48.
Smith, M. E., \& Ramunas, S. Elimination of visual field effects by use of a single report technique. Journal of Experimental Psychology, 1971, 87, 23-28.

Townsend, J. T., TAYLOR, S. G., \& BRown, D. R. Lateral masking for letters with unlimited viewing time. Perception \& Psychophysics, 1971, 10, 375-378.

White, M. J. Laterality differences in perception: A review. Psychological Bulletin, 1969, 72, 387-405.

WOLFORD, G., \& Hollingsworth, S. Lateral masking in visual information processing. Perception \& Psychophysics, 1974, 16, 315-320. (a)

Wolford, G., \& Hollingsworth, S. Retinal location and string position as important variables in visual information processing. Perception \& Psychophysics, 1974, 16, 437-442. (b)

(Received for publication May 18, 1978.) 